\title{
SIFAT MEKANIK PAVING BLOCK KOMPOSIT SEBAGAI LAPIS PERKERASAN BEBAS GENANGAN AIR (PERMEABLE PAVEMENT)
}

\author{
Iqbal Maulia ${ }^{1}$, Ismeddiyanto ${ }^{2}$, Reni Suryanita ${ }^{3}$ \\ Program Studi S1 Teknik Sipil, Fakultas Teknik, Universitas Riau \\ Kampus Bina Widya J. HR Soebrantas KM 12,5 Pekanbaru, Kode Pos 28293 \\ Email: iqbal.maulia@student.unri.ac.id, ismed.diyanto@lecturer.unri.ac.id,reni.suryanita@eng.unri.ac.id
}

\begin{abstract}
ABSTRAK
Penggunaan beton sebagai lapis perkerasan jalan dan pemukiman akan mempengaruhi proses infiltrasi sehingga mengakibatkan terjadi genangan atau banjir ketika musim hujan. Adapun alternatif untuk mengatasi masalah tersebut yaitu digunakan inovasi perkerasan paving block komposit. Paving block komposit merupakan penggabungan paving block dan beton porous. Penelitian ini bertujuan meningkatkan kuat tekan beton porous namun tidak mengurangi kemampuannya untuk meloloskan air dan mengkaji sifat mekanik yaitu kuat tekan. Pada penelitian ini beton porous diisi pada bagian tengah paving block dengan variasi diameter beton porous yang dibuat adalah 1 1/2", 2", 2 1/2”, dan 3". Pengujian kuat tekan dilakukan pada umur 28 hari. Pada pengujian kuat tekan, nilai tertinggi didapat dari masing-masing variasi berturut-turut adalah 39,260 MPa, 3,864 MPa, 21,747 MPa, dan 15,204 MPa. Klasifikasi paving block berdasarkan mutu kuat tekan didapat bahwa variasi $11 / 2$ " dan 2" termasuk kedalam mutu B, variasi $2 \frac{1 / 2}{2}$ " termasuk kedalam mutu C dan variasi 3" termasuk kedalam mutu D. Sehingga dapat disimpulkan nilai optimum kuat tekan inovasi paving block komposit yaitu sebesar 20,80 MPa dengan laju infiltrasi 2,78 mm/s. Nilai optimum tersebut termasuk kedalam mutu B yaitu pada variasi diameter 2" dan 2 $\frac{1}{2}$ ". Paving block komposit diameter 2" dan 21/2" ini dapat digunakan sebagai lahan parkir atau trotoar pejalan kaki dan mampu mengatasi banjir ataupun genangan air.
\end{abstract}

Kata Kunci: Beton Porous, Kuat Tekan, Paving Block Komposit

\begin{abstract}
The use of concrete as a layer of pavement will affect the process of infiltration at water into the ground resulting in flooding during the rainy season. The alternative to overcome this problem is to use composite paving block to replace the existing concrete paving block. Composite paving block is made of the combination between paving block and porous concrete. This research aims to increases the compressive strength of porous concrete without reducing its ability to absorb water into the ground and examine the mechanical properties of composite paving block. In this study, middle part of paving block was filled with porous concrete with the variations diameter of 11/2", 2", 21/2", and $3^{\prime \prime}$. The compressive strength was tested at 28 days after the specimen was casted. The result showed that the compressive strength at specimen with the porous part of 11/2", 2", 21/2", and 3" diameter was 39.260 MPa, 3.864 MPa, 21.747 MPa, and 15.204 MPa, respectively. According to the SNI 03-0691-1996, it was found that the specimens with the porous part of 11/2" and 2" diameter was classified as the paving block grade B, while specimen with porous part of 21/2" diameter was classified as the paving block with grade $C$ and the last was classified as grade D. Furthermore, from the regression analysis, it was found that the optimum size of porous part was the paving block with the diameter of $2^{\prime \prime}$ and $2^{1 / 2} 2^{\prime \prime}$. The compressive strength and the infiltration rate for these paving block were $20.80 \mathrm{MPa}$ and $2.78 \mathrm{~mm} / \mathrm{s}$, respectively. So it can be used as parking lots or pedestrian walkways and are able to overcome flooding or puddles.
\end{abstract}

Keywords: porous concrete, compressive strength, composite paving block 


\section{PENDAHULUAN}

Penggunaan beton salah satunya adalah sebagai bahan perkerasan jalan di daerah permukiman. Semakin meningkatnya luas daerah yang ditutupi oleh perkerasan seperti di daerah padat permukiman atau daerah perkotaan dapat mempengaruhi proses infiltrasi, yaitu air hujan tidak dapat menembus tanah sehingga menyebabkan terjadinya genangan dan melebihi kapasitas drainase yang ada. Hal ini mengakibatkan turunnya muka air tanah dan akhirnya terjadi banjir ketika musim hujan. Pembangunan jalan umumnya menggunakan perkerasan kaku dan perkerasan lentur yang kedap air, sehingga menyebabkan berkurangnya lahan hijau yang berdampak semakin sedikit daerah resapan air. Beberapa upaya telah dilakukan untuk mengantisipasi genangan air, seperti pembuatan paving block, sebatas hanya untuk konstruksi non structural seperti area parkir, trotoar untuk pejalan kaki, daerah lampu lalu lintas, dan lain-lain. Bata beton (paving block) memiliki kelebihan dibanding berbagai macam alternatif lain sebagai penutup atau pengerasan tanah. Selain paving block, beton porous juga bisa dijadikan sebagai penutup atau pengerasan tanah yang memiliki kemampuan meloloskan air. Beton porous merupakan jenis beton yang memiliki porositas tinggi dan diaplikasikan sebagai plat beton yang bias membuat air hujan serta sumber-sumber lain dapat menembus dan melewatinya, sehingga mengurangi genangan dan meningkatkan muka air tanah. Biasanya beton porous menggunakan sedikit atau tanpa agregat halus dan memiliki cukup pasta semen untuk melapisi permukaan agregat kasar dan untuk menjaga interkonektivitas pori [3]. Nilai kuat tekan beton porous lebih kecil atau lebih rendah dari nilai kuat tekan beton normal konvensional karena beton porous memiliki nilai porositas yang tinggi. Oleh karena itu, dengan mutu kuat tekan beton porous yang hingga saat ini masih rendah maka diperlukan penelitian ataupun inovasi untuk meningkatkan mutu beton porous ini dengan memperhatikan faktor - faktor yang mempengaruhi nilai kuat tekan beton, salah satunya dengan cara menggabungkan beton porous dengan paving block yang disebut paving block komposit. Dimana beton porous diisi pada bagian tengah paving block. Paving block akan menyelimuti beton porous sehingga beton porous tidak cepat hancur ketika diberi beban. Hal ini dilakukan untuk mendapatkan mutu kuat tekan yang tinggi tanpa mempengaruhi kemampuan meloloskan air dari beton porous sendiri.

\section{TINJAUAN PUSTAKA}

\subsection{Paving block}

Bata beton (paving block) adalah suatu komposisi bahan bangunan yang dibuat dari campuran semen portland atau bahan perekat hidrolis sejenisnya, air dan agregat dengan atau tanpa bahan tambahan lainnya yang tidak mengurangi mutu bata beton itu. Bata beton dapat berwarna seperti warna aslinya atau diberi zat warna pada komposisinya yang digunakan untuk halaman baik di dalam maupun di luar bangunan [4].

Paving block merupakan produk bahan bangunan yang biasa digunakan sebagai salah satu alternatif penutup permukaan tanah atau perkerasan. Paving block memiliki beragam variasi bentuk untuk memenuhi selera pemakai dan dapat dipakai sesuai kebutuhan. Paving block digunakan sesuai tingkat kebutuhannya, misalnya sebagai tempat parkir, terminal, trotoar, halaman rumah dan juga perkerasan jalan di komplek perumahan serta untuk keperluan lainnya.

\subsubsection{Syarat Mutu Paving Blok}

Syarat mutu paving block dalam SNI 030691-1996 adalah sebagai berikut:

a. Sifat tampak paving block harus mempunyai permukaan yang rata. Tidak terdapat retakretak dan cacat, bagian sudut dan rusuknya tidak mudah dipecahkan dengan kekuatan jari tangan.

b. Paving block harus mempunyai ukuran tebal nominal minimum $60 \mathrm{~mm}$ dengan toleransi \pm $8 \%$.

c. Paving block harus mempunyai sifat - sifat fisika seperti pada Tabel 1 berikut:

Tabel 1. Sifat - Sifat Fisik Paving Block

\begin{tabular}{cccccc}
\hline \multirow{2}{*}{ Mutu } & \multicolumn{2}{c}{$\begin{array}{c}\text { Kuat Tekan } \\
\text { (Mpa) }\end{array}$} & \multicolumn{2}{c}{$\begin{array}{c}\text { Ketahanan Aus } \\
(\mathrm{mm} / \text { menit })\end{array}$} & $\begin{array}{c}\text { Penyerapan } \\
\text { Air Rerata }\end{array}$ \\
& Rerata & Min & Rerata & Min & $(\%)$ \\
\hline A & 40 & 35 & 0,09 & 0,103 & 3 \\
B & 20 & 17 & 0,13 & 0,149 & 6 \\
C & 15 & 12,5 & 0,16 & 0,184 & 8 \\
D & 10 & 8,5 & 0,219 & 0,251 & 10 \\
\hline
\end{tabular}

Keterangan:

1. Paving block mutu A digunakan untuk jalan. Bata beton mutu A diatas disyaratkan kuat tekan minimal $35 \mathrm{MPa}$ dan rerata $40 \mathrm{MPa}$.

2. Paving block mutu B digunakan untuk peralatan parkir. Bata beton mutu B diatas disyaratkan kuat tekan minimal $17 \mathrm{MPa}$ dan rerata $20 \mathrm{MPa}$.

3. Paving block mutu $\mathrm{C}$ digunakan untuk pejalan kaki. Bata beton mutu $\mathrm{C}$ diatas disyaratkan kuat tekan minimal $12,5 \mathrm{MPa}$ dan rerata $15 \mathrm{MPa}$.

4. Paving block mutu D digunakan untuk taman dan penggunaan lain. Bata beton mutu D diatas disyaratkan kuat tekan minimal 8,5 $\mathrm{MPa}$ dan rerata $10 \mathrm{MPa}$. 
d. Paving block apabila diuji dengan natrium sulfat tidak boleh cacat, dan kehilangan berat yang diperkenankan maksimum $1 \%$.

Sedangkan syarat mutu paving block menurut British Standard 6717-1:1993 tentang Manufacturing Specification for Precast Concrete Paving Block adalah sebagai berikut:

a. Paving block sebaiknya memiliki ketebalan tidak kurang dari $60 \mathrm{~cm}$. Untuk paving block type $R$ (tipe persegi panjang) sebaiknya memiliki panjang $200 \mathrm{~mm}$ dan lebar $100 \mathrm{~mm}$. Sedangkan untuk paving block tipe $\mathrm{S}$ (tipe cacing) bentuk apapun dari tipe ini harus memiliki panjang garis $295 \mathrm{~mm}$.

b. Ukuran ketebalan paving block yang baik yaitu $60 \mathrm{~mm}, 65 \mathrm{~mm}, 80 \mathrm{~mm}$, dan $100 \mathrm{~mm}$.

c. Tali air yang terdapat di sekitar badan paving block sebaiknya mempunyai lebar tidak lebih dari $7 \mathrm{~mm}$.

d. Maksimum penyimpangan dimensi yang diizinkan pada paving block yaitu, panjang \pm $2 \mathrm{~mm}$, lebar $\pm 2 \mathrm{~mm}$, dan tebal $\pm 3 \mathrm{~mm}$.

Faktor koreksi kuat tekan pada paving block menurut ketebalannya terdapat dalam Tabel 2 berikut:

Tabel 2. Faktor Koreksi Kuat Tekan Paving Block menurut Ketebalannya

\begin{tabular}{ccc}
\hline $\begin{array}{c}\text { Ketebalan } \\
\text { Paving Block } \\
\text { (mm) }\end{array}$ & $\begin{array}{c}\text { Paving } \\
\text { Block Datar }\end{array}$ & $\begin{array}{c}\text { Paving Block } \\
\text { Bertali Air }\end{array}$ \\
\hline 60 atau 65 & 1,00 & 1,06 \\
80 & 1,12 & 1,18 \\
100 & 1,18 & 1,24 \\
\hline
\end{tabular}

\subsubsection{Material Penyusun Paving Block}

Material penyusun dari paving block adalah agregat halus, semen, air atau bahan tambah lainnya.

\subsection{Beton Porous}

Beton porous adalah beton tipe khusus dengan sifat permeabilitas yang tinggi, bobotnya yang ringan dan tidak / sedikit menggunakan butiran halus. Karena sifatnya tersebut, beton jenis ini dapat diaplikasikan sebagai lapis perkerasan yang memungkinkan air hujan atau air limpasan lainnya dipermukaan untuk melewatinya, sehingga dapat mengurangi genangan sekaligus dapat menaikkan muka air tanah. Sifat porositas tinggi tersebut dapat dicapai karena adanya kandungan rongga yang saling berhubungan.

\subsubsection{Bahan Penyusun Beton Porous}

Material penyusun dari beton porous adalah agregat kasar, semen, air atau bahan tambah lainnya.

\subsection{Bahan Tambah}

\subsubsection{Silica Fume}

Silica fume merupakan material pozoloan yang halus, dimana komposisi silika lebih banyak dihasilkan dari tanur tinggi atau sisa produksi silikon dan alloy besi silikon (dikenal sebagai gabungan antara microsilica dengan silica fume). Penggunaan silica fume dalam campuran beton dimaksudkan untuk menghasilkan beton dengan kekuatan tekan yang tinggi.

\subsubsection{Abu Batu}

Abu batu adalah bahan bangunan yang merupakan hasil dari proses penghancuran bongkahan batu yang digunakan untuk campuran beton. Kelebihan dari abu batu bila dibandingkan dengan menggunakan pasir, yang pertama adalah dari ukuran butirannya yang sangat kecil seperti debu atau abu dan ukurannya tersebut cukup merata ke seluruh bagiannya, sehingga dalam penggunaannya tidak diperlukan lagi proses pengayakan seperti saat kita menggunakan pasir.

\subsubsection{Fiber}

Fiber atau serat merupakan bahan dasar yang umum digunakan dalam memproduksi bahan bahan yang terbuat dari plastik. Pertama kali fiber digunakan dalam industri tekstil karena harganya murah dan dapat menghasilkan produk yang berkualitas. Material ini berbentuk filamen filamen yang ketika dicampurkan dalam adukan beton untaian itu akan terurai. Serat jenis ini dapat meningkatkan kuat tarik lentur dan tekan beton, mengurangi retak - retak akibat penyusutan, meningkatkan daya tahan terhadap impact dan meningkatkan daktilitas [5].

\subsection{Kuat Tekan}

Kuat tekan adalah besarnya beban persatuan luas, yang menyebabkan benda uji hancur bila dibebani dengan gaya tertentu, yang dihasilkan oleh mesin uji tekan. Kekuatan paving block biasanya tergantung pada bahan penyusunnya. Untuk memperoleh kuat tekan yang diinginkan maka perlu dilakukan proses perawatan.

Cara pengujian kuat tekan paving block menurut SNI-03-0691-1996 yaitu sebagai berikut:

a. Ambil 10 buah contoh uji masing-masing dipotong berbentuk kubus dan rusuk-rusuknya disesuaikan dengan ukuran contoh uji.

b. Contoh uji yang telah siap, ditekan hingga hancur dengan mesin penekan yang dapat diatur kecepatannya. Kecepatan penekanan dari mulai pemberian beban sampai contoh uji hancur, diatur dalam waktu 1 sampai 2 menit 
arah penakanan pada contoh uji disesuaikan dengan arah tekanan beban didalam pemakaiannya.

c. Kuat tekan dihitung dengan rumus sebagai berikut :

$$
\text { Kuat tekan }=\frac{P}{\mathrm{~L}}
$$

Keterangan:

$\mathrm{P}=$ beban tekan $(\mathrm{N})$

$\mathrm{L}=$ luas bidang tekan $\left(\mathrm{mm}^{2}\right)$

Kuat tekan rata-rata dari contoh uji dihitung dari jumlah kuat tekan dibagi jumlah contoh uji. Dalam reaksi dari pembebanan tekan (P) yang diberikan oleh mesin uji tekan (Compression Test Machine) akan diterima oleh seluruh daerah luasan penampang secara merata hingga terjadi keruntuhan pada benda uji beton.

\section{METODOLOGI PENELITIAN}

\subsection{Bahan Penelitian}

Bahan yang digunakan dalam penelitian ini yaitu : semen PCC, agregat kasar, agregat halus, air, dan bahan tambah berupa fiber, silica fume dan abu batu.

\subsection{Pengujian Karakteristik Material}

Pengujian karakteristik material dilakukan untuk mengetahui sifat atau karakteristik material yang akan digunakan.

\subsection{Perencanaan Campuran Beton}

Kompisisi campuran yang tepat pada paving block didapatkan dari nilai pengujian karakteristik material. Campuran pembuatan paving block terdiri dari semen, air, dan agregat halus dengan perbandingan tertentu. Komposisi campuran paving block untuk $1 \mathrm{~m}^{3}$ bisa dilihat pada Tabel 3 .

Tabel 3. Komposisi Campuran Paving Block

\begin{tabular}{cc}
\multicolumn{2}{c}{ Untuk $1 \mathrm{~m}^{3}$} \\
\hline Campuran Beton & Berat $(\mathrm{Kg})$ \\
\hline Semen & 416,67 \\
Air & 104,17 \\
Agregat Halus & 1612,96
\end{tabular}

\subsubsection{Perencanaan Pembuatan Benda Uji}

Pada tahap ini dilakukan perhitungan dan penimbangan berat masing-masing bahan, pengadukan bahan dilakukan dua tahap. Pertama, tahap pengadukan bahan paving block lalu dicetak sesuai cetakan dan dipadatkan, setelah itu letakkan paralon sesuai ukuran ditengah paving block sehingga pada bagian tengah paving block kosong. Kedua, tahap pengadukan bahan beton poros lalu dimasukkan ke bagian tengah paving block yang telah dikosongkan sebelumnya.
Paving block yang dibuat berbentuk segienam dengan panjang sisi $10 \mathrm{~cm}$ dan tebal 8 $\mathrm{cm}$. Bagian tengah paving block dilubangi dengan diameter 11/2", 2", 21/2" dan 3". Total sampel benda uji adalah 25 paving block. Rencana benda uji dapat dilihat pada Tabel 4 dan Gambar 1.

Tabel 4. Rencana Benda Uji

\begin{tabular}{|c|c|c|c|c|c|c|}
\hline \multirow{3}{*}{ Uji } & \multirow{3}{*}{$\begin{array}{l}\text { Paving } \\
\text { Block }\end{array}$} & \multicolumn{3}{|c|}{$\begin{array}{c}\text { Paving Block }+ \\
\text { Beton Porous }\end{array}$} & \multirow{2}{*}{\multicolumn{2}{|c|}{$\begin{array}{l}\text { Beton } \\
\text { Porous }\end{array}$}} \\
\hline & & \multicolumn{3}{|c|}{ Diameter Pipa } & & \\
\hline & & $11 / 2 "$ & $2 "$ & $\begin{array}{c}2 \\
1 / 2 "\end{array}$ & $\begin{array}{l}3 \\
\text { " }\end{array}$ & \\
\hline $\begin{array}{l}\text { Kuat } \\
\text { Tekan }\end{array}$ & 5 & 5 & 5 & 5 & 5 & 5 \\
\hline
\end{tabular}

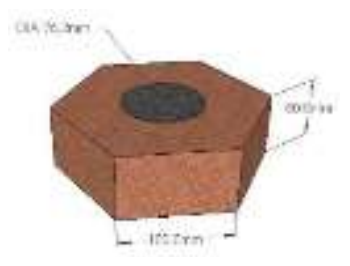

(a) Dimensi benda uji

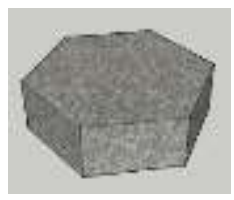

(b) Paving block

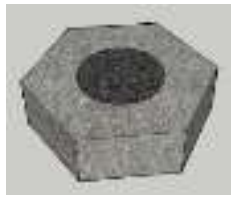

(e) Paving block komposit $2 \frac{1}{2}$ "

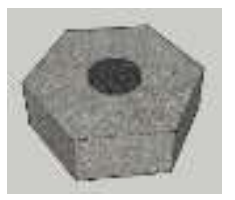

(c) Paving block komposit $1 \frac{1}{2}$ "

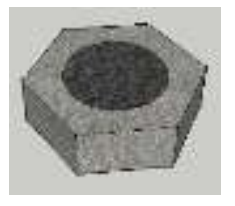

(f) Paving block komposit 3"

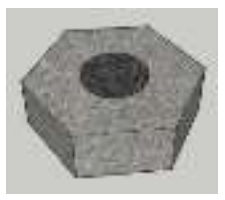

(d) Paving block komposit 2"

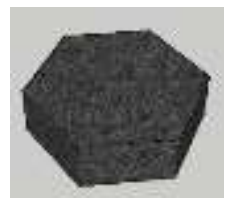

(g) Beton porous
Gambar 1. Sketsa Benda Uji

\subsubsection{Pelaksanaan Pembuatan Benda Uji}

Pembuatan benda uji berdasarkan komposisi dan rencana benda uji yang telah direncanakan. Pembuatan paving block dilaksanakan di tempat pembuatan paving block di Jalan Pesantren, Tenayan Raya dan pembuatan beton porous dilaksanakan di Laboratorium Teknologi Bahan Jurusan Teknik Sipil Fakultas Teknik, Universitas Riau.

Proses pembuatan paving block komposit ini sama seperti pembuatan paving block pada umumnya yaitu menggunakan cetakan dan mesin penggetar hanya saja yang membedakan ketika adukan akan dipadatkan, pipa diletakkan didalam cetakan sesuai dengan variasi diameter untuk 
nantinya akan diisi dengan beton porous seperti terlihat pada Gambar 2.

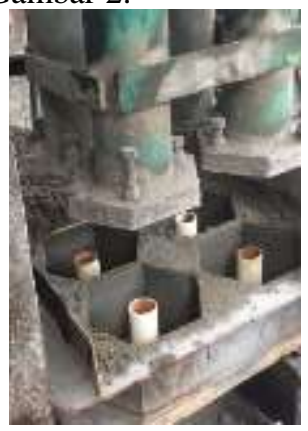

Gambar 2. Meletakkan Pipa dalam Cetakan

Setelah adukan dipadatkan, paving block dikeluarkan dari cetakan dan mengeluarkan pipa sebelum paving block mengeras seperti terlihat pada Gambar 3.

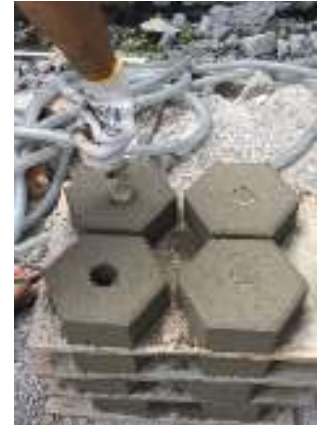

Gambar 3. Mengeluarkan Pipa

Proses pembuatan beton porous dilakukan secara manual tanpa ada bantuan mesin pengaduk karena campuran yang sedikit dan cepat mengeras. Pembuatan beton porous dilaksanakan setelah paving block kering karena adukan beton porous langsung dimasukkan kedalam paving block yang telah dilubangi seperti terlihat pada Gambar 4.

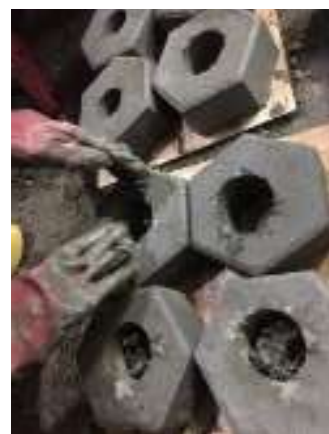

Gambar 4. Mengisi Beton Porous

Selanjutnya untuk variasi beton porous ukuran segienam menggunakan cetakan kayu yang telah disiapkan seperti terlihat pada Gambar 5. Kemudian setelah \pm 24 jam membuka cetakan beton porous dan melakukan curing selama 28 hari.

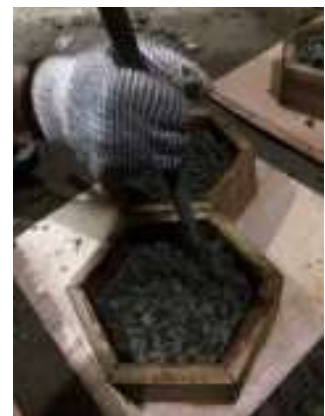

Gambar 5. Mengisi Beton Porous kedalam Cetakan

\subsection{Perawatan Benda Uji (Curing)}

Perawatan benda uji berfungsi agar proses hidrasi beton menjadi sempurna. Setelah benda uji mengeras, dilakukan perawatan pada beton. Perawatan dilakukan dengan cara menyelimuti benda uji menggunakan goni basah dan ditutup plastik agar goni tidak cepat kering selama 28 hari seperti terlihat pada Gambar 6.

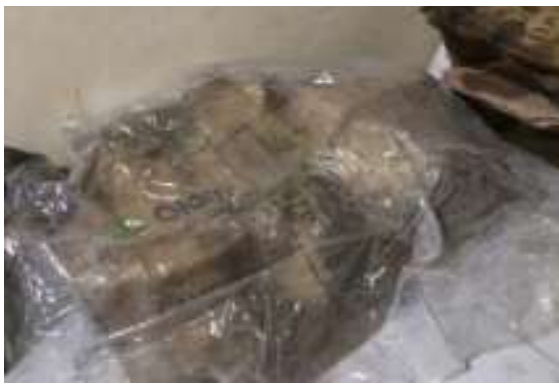

Gambar 6. Perawatan Benda Uji

\subsection{Pelaksanaan Pengujian Benda Uji}

Pelaksaan pengujian benda uji dilakukan untuk menentukan kekuatan dan kualitas benda uji terhadap tekanan yang diberikan. Pengujian yang dilakukan berupa pengujian sifat mekanik beton yaitu kuat tekan. Pengujian kuat tekan dilakukan pada umur beton 28 hari.

Pengujian kuat tekan dilaksanakan berdasarkan SNI 03-0691-1996 yang bertujuan untuk menentukan kemampuan bata beton (paving block) dalam menerima gaya per satuan luas. Prosedur pengujian kuat tekan paving block adalah pertama, goni basah penutup benda uji dibuka sehari sebelum pengujian kuat tekan. Selanjutnya benda uji ditimbang dan ditekan dengan mesin uji tekan sampai hancur.

\section{HASIL DAN PEMBAHASAN}

4.1 Hasil Pengujian Karakteristik Material Campuran Beton

Hasil pemeriksaan karakteristik agregat kasar dan halus dapat dilihan pada Tabel 3 dan 4.

lqbal, Sifat Mekanik Paving Block Komposit Sebagai Lapis Perkerasan Bebas Genangan Air (Permeable Pavement) 
Tabel 5. Hasil Pengujian Karakteristik Agregat Kasar

\begin{tabular}{|c|c|c|c|}
\hline No & Jenis Pemeriksaan & $\begin{array}{c}\text { Hasil } \\
\text { Pengujian }\end{array}$ & $\begin{array}{c}\text { Standar } \\
\text { Spesifikasi }\end{array}$ \\
\hline 1 & Kadar air $(\%)$ & 2,93 & $<5,00$ \\
\hline \multirow[t]{5}{*}{2} & Berat Jenis $(\mathrm{g} / \mathrm{cm} 3)$ & & \\
\hline & $\begin{array}{l}\text { a. Apparent specific } \\
\text { Gravity }\end{array}$ & 2,66 & $2,58-2,83$ \\
\hline & $\begin{array}{l}\text { b. } \begin{array}{l}\text { Bulk specific } \\
\text { gravity } \\
\text { (kering) }\end{array} \\
\end{array}$ & 2,51 & $2,58-2,83$ \\
\hline & $\begin{array}{l}\text { c. Bulk specific } \\
\text { gravity } \\
\text { (ssd) }\end{array}$ & 2,56 & $2,58-2,83$ \\
\hline & d. Absorption (\%) & 2,22 & $2,00-7,00$ \\
\hline \multirow[t]{3}{*}{3} & Berat volume $\left(\mathrm{g} / \mathrm{cm}^{3}\right)$ & & \\
\hline & a. Kondisi gembur & 1,36 & $1,40-1,90$ \\
\hline & b. Kondisi padat & 1,48 & $1,40-1,90$ \\
\hline 4 & Ketahanan aus (\%) & 47,62 & $<40$ \\
\hline 5 & Modulus kehalusan & 6,75 & $5,00-8,00$ \\
\hline
\end{tabular}

Tabel 6. Hasil Pengujian Karakteristik Agregat Halus

\begin{tabular}{|c|c|c|c|}
\hline No & Jenis Pemeriksaan & Hasil Pengujian & $\begin{array}{l}\text { Standar } \\
\text { Spesifikas }\end{array}$ \\
\hline 1 & Kadar air $(\%)$ & 2,99 & $<5,00$ \\
\hline \multirow[t]{5}{*}{2} & Berat Jenis $(\mathrm{g} / \mathrm{cm} 3)$ & & \\
\hline & $\begin{array}{l}\text { a. Apparent specific } \\
\text { Gravity }\end{array}$ & 2,64 & $2,58-2,83$ \\
\hline & $\begin{array}{l}\text { b. Bulk specific } \\
\text { gravity } \\
\text { (kering) }\end{array}$ & 2,58 & $2,58-2,83$ \\
\hline & $\begin{array}{l}\text { c. Bulk specific } \\
\text { gravity } \\
(s s d)\end{array}$ & 2,60 & $2,58-2,83$ \\
\hline & d. Absorption (\%) & 0,91 & $2,00-7,00$ \\
\hline \multirow[t]{3}{*}{3} & $\begin{array}{l}\text { Berat volume } \\
(\mathrm{g} / \mathrm{cm} 3)\end{array}$ & & \\
\hline & a. Kondisi gembur & 1,42 & $1,40-1,90$ \\
\hline & b. Kondisi padat & 1,61 & $1,40-1,90$ \\
\hline 4 & Modulus kehalusan & 2,46 & $1,50-3,80$ \\
\hline 5 & Kadar lumpur (\%) & 2,26 & $<5$ \\
\hline 6 & Kandungan organik & No.3 & $<$ No.3 \\
\hline
\end{tabular}

\subsection{Hasil Pengujian Kuat Tekan}

Pada penelitian ini didapatkan beberapa hasil kuat tekan berdasarkan variasi benda. Untuk setiap variasi telah diuji sebanyak lima sampel bentuk segienam sisi $10 \mathrm{~cm}$ dan tebal $8 \mathrm{~cm}$. Selanjutnya hasil pengujian kuat tekan dapat dilihat pada Tabel 7 dan Gambar 7.

Tabel 7. Nilai Kuat Tekan

\begin{tabular}{cc}
\hline $\begin{array}{c}\text { Kode Benda } \\
\text { Uji }\end{array}$ & $\begin{array}{c}\text { Kuat Tekan Rerata } \\
(\mathrm{MPa})\end{array}$ \\
\hline Paving Block & 48,190 \\
$1 \frac{112 "}{2}$ & 36,335 \\
$2 "$ & 22,093 \\
$2 \frac{1}{2} "$ & 19,591 \\
$3 ”$ & 13,702 \\
Beton Porous & 11,893 \\
\hline
\end{tabular}

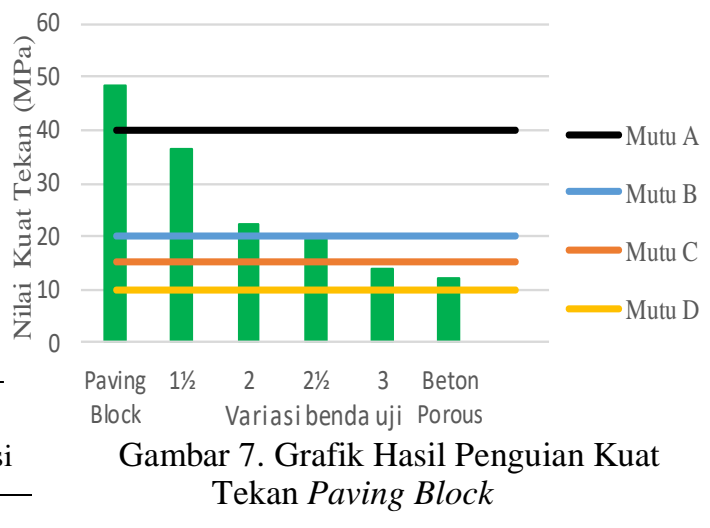

Berdasarkan hasil pengujian didapat nilai kuat tekan paving block penuh 48,190 MPa, kuat tekan paving block dengan diameter porous $1 \frac{1}{2}$ ", $36,335 \mathrm{MPa}$, diameter porous 2" 22,093 $\mathrm{MPa}$, diameter porous $2 \frac{1}{2} " 19,591 \mathrm{MPa}$, diameter porous 3" $13,702 \mathrm{MPa}$ dan beton porous penuh 11,893 MPa. Nilai kuat tekan yang didapat tidak beraturan setiap variasinya dikarenakan posisi lubang cetakan beton porous yang tidak tepat ditengah dan juga tinggi beton porous yang tidak sama rata dengan paving block.

Dari hasil pengujian didapat bahwa nilai kuat tekan paving block penuh termasuk kedalam mutu A, paving block komposit diameter porous $1 \frac{1}{2}$ ", dan 2" termasuk kedalam mutu B, diameter porous $2 \frac{1}{2}$ " termasuk kedalam mutu $\mathrm{C}$, diameter porous 3" dan beton porous penuh termasuk kedalam mutu D.

Sedangkan nilai kuat tekan maksimum paving block penuh 50,807 $\mathrm{MPa}$, paving block komposit diameter porous 11/2" 39,260 Mpa, diameter porous 2" 23,864 MPa, diameter porous $2 \frac{1}{2}$ " 21,747 $\mathrm{MPa}$, diameter porous 3" $15,204 \mathrm{MPa}$ dan beton porous penuh 12,894 $\mathrm{MPa}$. 


\subsection{Hubungan Kuat Tekan dan Laju Infiltrasi}

Tujuan utama dari penelitian ini adalah mempertahankan kemampuan meloloskan air dari beton porous dan tetap mendapatkan kuat tekan yang tinggi. Untuk mengetahui tercapainya tujuan dari penelitian ini diperlukan data laju infiltrasi untuk menghubungkan kuat tekan dan laju infiltrasi. Sehingga dapat diperoleh variasi paving block komposit yang menghasilkan nilai lolos air yang bagus dan juga mutu yang tinggi. Seperti terlihat pada Tabel 8 dan Gambar 8.

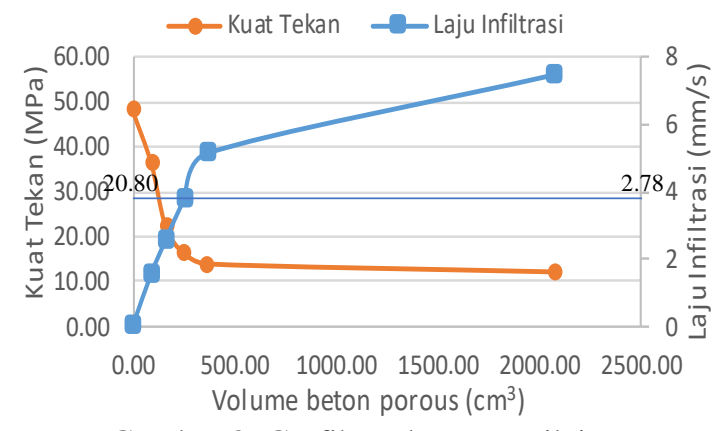

Gambar 8. Grafik Hubungan Nilai Kuat Tekan dan Laju Infiltrasi

\begin{tabular}{ccc}
\multicolumn{3}{c}{ Tabel 8. Nilai Kuat Tekan dan Laju Infiltrasi } \\
\hline $\begin{array}{c}\text { Kode } \\
\text { Benda } \\
\text { Uji }\end{array}$ & $\begin{array}{c}\text { Kuat Tekan } \\
\text { Rata-rata } \\
\text { (MPa) }\end{array}$ & $\begin{array}{c}\text { Laju } \\
\text { Infiltrasi } \\
(\mathrm{mm} / \mathrm{s})\end{array}$ \\
\hline Paving & 48.190 & 0.013 \\
$11 / 2 "$ & 36.335 & 1.56 \\
$2 "$ & 22.093 & 2.56 \\
$21 \frac{1}{2} "$ & 19.591 & 3.78 \\
$3 ”$ & 13.702 & 5.13 \\
Porous & 11.893 & 7.47
\end{tabular}

Dari grafik hubungan nilai kuat tekan dan laju infiltrasi didapat titik nilai optimum dengan nilai kuat tekan sebesar 20,80 $\mathrm{MPa}$ dan nilai laju infiltrasi sebesar $2,78 \mathrm{~mm} / \mathrm{s}$. nilai optimum tersebut berada pada variasi paving block komposit 2 " dan 21/2". Berdasarkan klasifikasi mutu menurut SNI 03-0691-1996, nilai kuat tekan 20,80 MPa termasuk ke dalam mutu B untuk lahan parkir. Dapat disimpulkan bahwa inovasi paving block komposit pada penelitian ini dapat digunakan sebagai lapis perkerasan untuk lahan parkir, trotoar pejalan kaki yang mampu mengatasi banjir ataupun genangan air terutama pada musim hujan.

\section{KESIMPULAN DAN SARAN}

\subsection{Kesimpulan}

Berdasarkan hasil pengujian yang dilakukan terhadap beton pada penelitian ini, maka dapat diambil kesimpulan sebagai berikut:

1. Nilai kuat tekan kombinasi paving block dan beton porous lebih tinggi dibandingkan nilai kuat tekan beton porous dengan dimensi yang sama. Nilai kuat tekan beton porous 11,893 $\mathrm{MPa}$, kombinasi paving block dan beton porous diameter 11/2"; 2"; 21/2"; 3" memiliki nilai kuat tekan berturut - turut $36,335 \mathrm{MPa}$; 22,093 MPa; 19,591 MPa; 13,702 $\mathrm{MPa}$. Sedangkan nilai kuat tekan paving block 48,190 MPa.

2. Nilai kuat tekan kombinasi paving block dan beton porous maksimum terjadi pada variasi diameter 11/2" yaitu 39,260 MPa.

3. Klasifikasi paving block berdasarkan mutu kuat tekan didapat bahwa paving block termasuk kedalam mutu A, kombinasi paving block dan beton porous diameter 11/2" dan 2" termasuk kedalam mutu B, kombinasi paving block dan beton porous diameter $2 \frac{1 / 2}{2}$ " termasuk kedalam mutu $\mathrm{C}$, kombinasi paving block dan beton porous diameter 3" dan beton porous termasuk kedalam mutu D.

4. Dapat disimpulkan nilai optimum kuat tekan inovasi paving block komposit yaitu sebesar $20,80 \mathrm{MPa}$ dengan laju infiltrasi $2,78 \mathrm{~mm} / \mathrm{s}$. Nilai optimum tersebut termasuk kedalam mutu B yaitu pada variasi diameter 2" dan 21/2". Paving block komposit diameter 2" dan $2 \frac{1}{2}$ " ini dapat digunakan sebagai lahan parkir atau trotoar pejalan kaki dan mampu mengatasi banjir ataupun genangan air.

\subsection{Saran}

Berdasarkan penelitian yang telah dilakukan, perlu beberapa saran untuk ditindaklanjuti yaitu sebagai berikut:

1. Sebaiknya dalam proses pembuatan lubang cetakan beton porous pada paving block perlu memperhatikan posisi pipa agar lubang tepat berada ditengah setelah paving block dipadatkan.

2. Untuk proses pembuatan paving block komposit disarankan melakukan perlakuan yang sama agar tidak terjadi perbedaan sifat mekanik antar benda uji.

3. Perlu dilakukan pengujian pada persentase bahan tambah yang berbeda untuk mengetahui pengaruh penggunaan bahan tambah pada campuran paving block komposit. 
4. Perlu dilakukan penelitian lebih lanjut mengenai penggunaan paving block komposit dilapangan.

\section{DAFTAR PUSTAKA}

[1] Badan Standarisasi Nasional. (1996). SNI 030691-1996 Bata Beton (Paving Block). Jakarta: Badan Standarisasi Nasional.

[2] British Standard 6717-1. (1993). Manufacturing Specification for Precast Concrete Paving Block.

[3] Ginting, A. (2015). Pengaruh Rasio Agregat Semen Dan Faktor Air Semen Terhadap Kuat Tekan Dan Porositas Beton Porous. Jurnal Teknik, 1-9.

[4] Sumaryanto, D., Satyarno, I., \& Tjokrodimulyo, K. (2009). Batako Sekam Padi Komposit Mortar Semen.

[5] Wahyu, K. (2007). Penggunaan Serat Polypropylene Untuk Meningkatkan Kuat Tarik Belah Beton. Jurnal Rekayasa Perencanaan. 